\title{
Incentives, information, rehearsal, and the negative recency effect*
}

\author{
LEAH L. LIGHT $\dagger$ \\ Pitzer College, Claremont, California 91711
}

\begin{abstract}
The negative recency effect is generally attributed to inadequate rehearsal of terminal input items during study. In two experiments, Ss were encouraged to increase rehearsal of initial or terminal input items by offers of incentives for remembering these items and information that there would be a delayed memory test (Experiment 1 ) or by explicit instructions to rehearse terminal items and provision of added rehearsal time (Experiment II). Serial position curves in immediate and delayed recall were little affected by these manipulations. These results are more in line with models that give rehearsal the role of maintaining items in a short-term store than with models that accord rehearsal a role in transfer of information to a more permanent store.
\end{abstract}

In single-trial probed recall of short lists of paired associates, items in terminal input positions are nearly always recalled correctly on an immediate test and virtually never recalled on an unannounced delayed test (Madigan \& McCabe, 1971; McCabe \& Madigan, 1971). Similar phenomena have been reliably demonstrated for single-trial free recall (e.g., Bartz, Lewis, \& Swinton, 1972; Craik, 1970; Craik, Gardiner, \& Watkins, 1970; Darley \& Murdock, 1971), single-trial serial recall (Cohen, 1970), and recognition (Craik et al, 1970; Darley \& Murdock, 1971; McCabe \& Madigan, 1971; Rundus, Loftus, \& Atkinson, 1970), although Cohen (1970) did not find a deficit for terminal input items in recognition. Some investigators have reported that in final testing terminal input items are remembered more poorly than any other portion of the list; for this reason, Craik (1970) has called the phenomenon the "negative recency effect." Others, however, have failed to find negative recency but have reported nonpositive recency effects; Bartz, Lewis, and Swinton (1972) refer to this pattern of results as "positive primacy."

Regardless of whether negative recency or positive primacy is being discussed, the most common explanation of the phenomenon is in terms of a two-store memory model, usually that of Atkinson and Shiffrin (1968). As items are presented for study, they enter a short-term store (STS) in which they may or may not be rehearsed. Rehearsal serves at least two functions. First, it maintains items in STS, and, second, during rehearsal information about items is transferred to the more permanent long-term store (LTS). The amount of

*This research was supported by grants from the Pitzer College Community Council to Bruce Ross and from the Pitzer College Research and Development Committee to the author. Sharon Friedman performed both experiments. C. Rubin, G. Holmes, and D. Saunders assisted in the data analysis. Special thanks are due M. P. Friedman and W. P. Banks for providing research facilities and Dale Berger for help on statistical questions.

$†$ Reprints should be requested from Leah L. Light, Department of Psychology, Pitzer College, Claremont, California 91711. information transferred to LTS is a function of the number of rehearsals given an item and determines the ease with which an item may subsequently be retrieved from LTS. Items in initial input positions generally receive more rehearsals and, thus, should be more readily retrieved from LTS than items in later input positions (Rundus \& Atkinson, 1970; Rundus, 1971). When items are tested immediately after presentation, terminal items may be retrieved from STS. However, on delayed tests items from terminal input positions fare poorly because they are no longer in STS and less information about them has been transferred to LTS relative to items in initial list positions.

In most studies of the negative recency effect, Ss are unaware that they will be given a delayed test. For instance, Madigan and McCabe (1971) presented Ss with 50 lists of five paired associates and followed each list with an immediate probe of one of the five serial positions. After the 50 lists had been presented, Ss were given a final test on all lists. Under these circumstances, terminal list items may be retrieved from STS during the immediate test and may not be rehearsed much at all, since Ss have no expectation of a subsequent test on all lists. The two studies reported here attempted (unsuccessfully) to manipulate rehearsal strategies of Ss so that more information about items in terminal input positions might be transferred to LTS and the magnitude of the negative recency effect in single-trial probed recall of paired associates might thereby be reduced. In Experiment I, Ss were informed that there would be a delayed test and were offered monetary incentives for correct responses to either first or fifth (final) position items on the delayed test. When varied over items in the same list, monetary incentives are known to affect retention (e.g., Harley, 1965a, b; Loftus \& Wickens, 1970 ), and there is convincing evidence that such effects are the result of altered rehearsal strategies (Montague, Hillix, Kiess, \& Harris, 1970). Thus, in Experiment I it was predicted that, relative to a control group, Ss offered money to remember first position items would show enhanced primacy and Ss offered money to 
remember final items would show enhanced recency on a delayed test. In Experiment II, all Ss were informed of the delayed test in advance. Some Ss were explicitly instructed to rehearse final input items in each list until the probe was presented, and these Ss were also given a silent delay prior to presentation of the probe. The prediction here was that providing additional rehearsal time for terminal items and instructing Ss to rehearse these items should result in increased transfer of information to LTS and a diminished negative recency effect.

\section{EXPERIMENT I}

A pilot study by Bruce Ross replicated Madigan and McCabe's (1971) study using materials supplied by Madigan. Two groups were involved. A control group received no instructions about the delayed test. The incentive group was informed that a final test would follow the 50 paired-associate lists, that Ss often had difficulty remembering items from the ends of lists, that they should attend carefully to these items, that correct responses on the final test on items from the fourth and fifth input positions were worth 10 cents each, and that the $S$ whose overall final performance was highest would receive an additional $\$ 5$ prize. After each 10 lists, Ss in the incentive condition were reminded that they should attend to the fourth and fifth list pairs. The results of this pilot study were quite surprising: Incentives had no effect whatsoever on performance on either the immediate or the delayed test, and both the control group and the incentive group displayed negative recency on the delayed test. One possible explanation of these results is that the information given to $S s$ in the incentive group convinced them that it would be very difficult to remember items in the last two positions and that they, therefore, did not attempt to do so (i.e., did not rehearse these items more). ${ }^{1}$

Experiment I replicated Ross's study with two major modifications. First, a second incentive condition was added; Ss were rewarded for remembering the last pair in each list or for remembering the first pair in each list. Even though Ss are given an incentive to remember the last pair in each list, they may not have adequate time for rehearsal prior to probe presentation, since the probe follows immediately after the last pair in each list. However, Ss offered an incentive to remember first pairs should be able to increase the amount of time spent on rehearsing these items and should demonstrate an enhanced primacy effect relative to a control group given neither advance information about the delayed test nor incentives. Second, Ss in incentive conditions were not told that it was difficult to retain particular items but only that $E$ was "particularly interested" in either the first or the last pair from each list and that a correct response on each such pair on the delayed test would be worth 25 cents.

\section{Method}

\section{Materials}

Forty-two lists of five paired associates were randomly generated from a pool consisting of two-syllable words having Thorndike-Lorge (1944) A or AA frequencies. Two of these lists served as practice lists. All Ss were tested with the same set of 40 experimental lists but two different orders of probes for the immediate test were used. For both probe orders, each of the five list positions was tested once in each block of five lists. Order of probes within blocks was random, with the constraint that no pair could be used in both probe orders. There were, thus, eight tests on each of the five list positions on the immediate test.

All lists were tape recorded. The presentation rate was $5 \mathrm{sec} / \mathrm{pair}$, with the second member of a pair following the onset of the first member by about $2 \mathrm{sec}$ and approximately $2 \mathrm{sec}$ of silence between pairs. The probe followed each list as though it were the first member of a six th pair and $S$ was allowed $10 \mathrm{sec}$ to make a response before the next list began. All responses were oral and were recorded by $\mathrm{E}$.

The delayed test was written. All 80 stimuli from the two probe orders were printed on a single sheet of paper, with space provided for $S$ to write the response members of the pairs. Within successive blocks of 10 items, each input position was tested twice (with one probe from each probe order). There were 16 tests on each position on the delayed test. For a given S, eight of these were previously tested (PT) pairs and eight were previously untested (NPT) pairs.

\section{Procedure}

Those Ss who served in the control condition were simply told that the experiment concerned memory for short lists of words. A practice list was presented and S's task was described as trying to "remember which words go together in pairs." A second practice list followed. All Ss were encouraged to guess if they were unsure of the correct response to a probe. No information about a forthcoming delayed test was given.

Those Ss who served in the two incentive conditions (Group 1 and Group 5) were given the following additional instructions: "There will also be a second test on all the lists after we have been through the tape once. On this second test will be all the pairs you were tested on before plus some pairs from the lists on which you were not tested before. I am particularly interested in the first (last) pair from each list. For each first (last) pair that you get right on the second test, I will pay you an additional quarter. Since there will be 16 tests on first (last) pairs, you will have the opportunity to earn an additional $\$ 4$ if you get all the first (last) pairs correct on the delayed test."

The final test was administered immediately after the last list was presented. Unlimited time was permitted for this test.

\section{Subjects}

Twelve Ss served in each of the three experimental conditions. Of these, 2 were students in an introductory psychology course at the University of California, Los Angeles, whose participation fulfilled a course requirement, and 10 were paid volunteers who responded to a newspaper advertisement. Six Ss in each condition, 1 introductory psychology student and 5 paid volunteers, were tested with each probe order. All Ss were tested individually.

\section{Results}

The number of correct responses at each serial position on the immediate and delayed tests was 
computed for each S. Although subsequent statistical analyses dealt with number of correct responses, to facilitate comparison of the present results with past research the mean numbers of correct responses for the immediate and delayed PT tests have been expressed in Fig. 1 as proportions correct. It is quite clear from Fig. 1 that informing Ss of a delayed test and offering incentives for retention of particular list items had little if any effect on performance on those items on either the immediate test or the delayed test on PT items. The negative recency effect is very much in evidence here for all conditions. Terminal input items were almost invariably recalled on the immediate test but were rarely recalled on the delayed test.

The points plotted for the delayed test in Fig. 1 include both items that were correctly recalled on the immediate test and "reminiscence" items that were not correctly recalled on the immediate test (see Craik et al, 1970). Ss in the three experimental conditions produced a total of eight reminiscence items. Although no reminiscence items came from the fifth list position, they were fairly evenly distributed over the remaining four list positions. Deleting these reminiscence items would not materially affect the pattern of results depicted in Fig. 1.

The visual impression conveyed by Fig. 1 was confirmed by analysis of variance, with number correct serving as the response measure. The analysis of variance included six factors: incentive conditions (control, first position, fifth position), probe orders (two probe orders), Ss, tests (immediate, delayed-PT items, delayed-NPT items), positions (1-5), and halves of the experiment. The Ss factor was treated as a random factor nested under incentive conditions and probe orders; all other factors were fixed. The last factor, halves of the experiment, was included because it has been argued (e.g., Bartz et al, 1972) that, as Ss gain experience with the conditions of short-term memory studies, they learn that they may recall terminal list items from STS and need not rehearse them; also, rehearsal of initial input items increases. In the present experiment, it is useful to be able to determine whether Ss in the two incentive conditions shift their rehearsal strategies in ways other than Ss in the control group do.

Neither the main effect of incentives $[F(2,30)=.22$, $\mathrm{MSE}=3.64]$ nor any interactions involving the incentive factor were significant at the .05 level. $^{2}$ The main effect of tests was significant $[F(2,60)=616.53, \mathrm{MSE}=.73$, $\mathrm{p}<.0011$. Subsequent orthogonal planned comparisons indicated significant differences between the two delayed tests $[\mathrm{F}(1,60)=43.04, \mathrm{MSE}=.0030]$ and between the immediate test and the mean of the two delayed tests $[F(1,60)=1201.53$, MSE $=.012$, both ps $<.001]$. Performance is considerably better on PT items than on NPT items on the delayed test. The total numbers of correct responses on PT items were 79, 82, and 77 for the control group, Group 1, and Group 5, respectively, as compared to totals of 27,35 , and 47 correct responses on NPT items for the three groups.

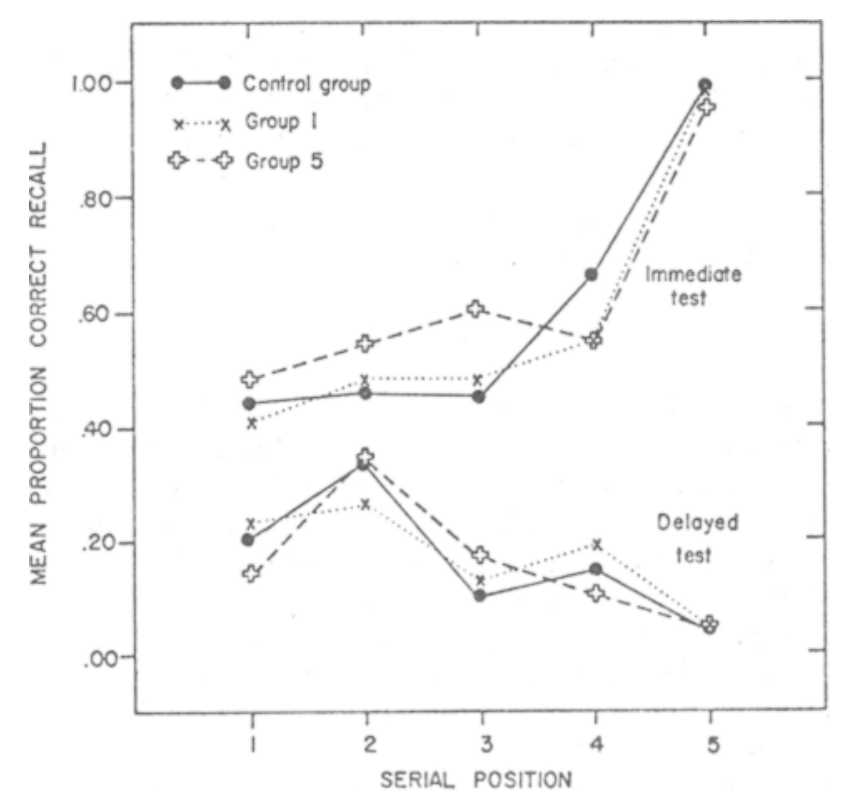

Fig. 1. Mean proportion of correct responses on immediate and delayed tests as a function of serial input position and incentive condition in Experiment $I$.

This result replicates previous findings (e.g., Darley \& Murdock, 1971; Madigan \& McCabe, 1971) and is presumably due to increased practice in retrieval from LTS for the PT items.

The main effect of serial positions was significant $[F(4,120)=12.95, \mathrm{MSE}=.67, \mathrm{p}<.001]$, as was the Tests by Serial Positions interaction $[F(8,240)=66.49$, MSE $=.44, p<.001]$. This interaction is due primarily to differences in serial position curves for the immediate test and the two delayed tests that exhibit similar serial positions effects. Orthogonal contrasts were performed on the interaction components. Although there is some slight difference in shape for the two delayed test curves $[\mathrm{F}(4,240)=2.77, \mathrm{MSE}=.44, \mathrm{p}<.05]$, a contrast between the mean of these two curves and the curve for the immediate test produced an $\mathrm{F}(4,240)=130.21$, MSE $=.44, p<.001 ;$ the latter contrast accounts for .98 of the total Tests by Serial Positions interaction variation. Although it might appear from Fig. 1 that, as predicted, Ss in Group 1 performed better on items from the first input position on the delayed test, a one-way analysis of variance yielded a nonsignificant $F(2,33)=$ $1.96, \mathrm{MSE}=.89, \mathrm{p}>.10$ for the PT items.

In addition, the two probe orders differed in difficulty $[F(1,30)=4.71, \mathrm{MSE}=3.64, \mathrm{p}<.05]$. The Probe Order by Tests and the Probe Order by Tests by Serial Positions interactions were also significant $[F(2,60)=13.39, \mathrm{MSE}=.73, \mathrm{p}<.001$ and $\mathrm{F}(8,240)=$ $7.12, \mathrm{MSE}=.44, \mathrm{p}<.001$, respectively]. These interactions reflect the uninteresting facts that performance was better on one of the probe orders than on the other on all three tests and that the superiority was more marked for initial than for terminal list positions.

Finally, the Positions by Halves of the Experiment 
and Tests by Positions by Halves of the Experiment interactions were both significant $[F(4,120)=5.70$, $\mathrm{MSE}=.67, \mathrm{p}<.001$ and $\mathrm{F}(8,240)=2.62, \mathrm{MSE}=.39$, $p<.05]$. Unfortunately, items in the two halves of the experiment were not counterbalanced and the interactions are not readily interpretable in terms of any current theoretical notions.

\section{Discussion}

The lack of effect of incentives and advanced information about a delayed test on the shape of the serial position curve in either immediate or delayed testing was unexpected. One explanation for this finding would be that, contrary to Atkinson and Shiffrin (1968), rehearsal is not a control process. Such an explanation is difficult to maintain in the face of considerable evidence to the contrary. Rundus (1971, Experiment II) has directly demonstrated that instructing Ss to attend carefully to particular items and to remember them increases rehearsal of these items. Several studies have dealt less directly with the effects of altered rehearsal patterns on free recall. For example, when rehearsal of initial list items is reduced or prevented by presenting a free recall list in an incidental learning situation (Marshall \& Werder, 1972) or by manipulating rehearsal strategies by instructions (Fischler, Rundus, \& Atkinson, 1970; Glanzer \& Meinzer, 1967; Palmer \& Ornstein, 1971), the primacy effect in immediate recall is reduced or eliminated, while the recency effect continues to be present. On the other hand, if rehearsal of terminal input positions is hampered by introducing a filled delay interval before the immediate test, the recency effect is reduced, while primacy continues to be manifested (Glanzer \& Cunitz, 1966; Postman \& Phillips, 1965).

Such results make it increasingly difficult to understand why the serial position curve in immediate testing was not responsive to offers of incentives. The lack of effect for the last input position may be due to a ceiling effect, as performance for the control group was virtually perfect. More perplexing is the finding that the primacy portion of the serial position curve was no different for Group 1 than for the control group in the immediate test, since there is no question of inadequate rehearsal time here: It may be noted in this context that Ss were not specifically instructed to rehearse the pairs for which incentives were offered and that Ss' task was described as "remembering which words go together in pairs." Palmer and Ornstein (1971) report a drastically reduced primacy effect for immediate probed recall when Ss are instructed to rehearse items in pairs [the $n^{\text {th }}$ item and the $(n-1)^{\text {th }}$ item] during list presentation. If Ss in the current study rehearsed pairs primarily as they were presented and rarely rehearsed previously presented pairs, one might expect to find the kind of serial position curve found here, namely one characterized by marked recency and minimal primacy.

As far as the delayed test is concerned, if incentive offers did not materially affect rehearsal strategy of Ss in Group 1, the lack of enhanced primacy might be anticipated. Also, it is conceivable that Ss in Group 5 had insufficient time for increased rehearsal prior to probe presentation. However, the presentation rate in the present study was relatively slow and instructions designed to manipulate rehearsal strategies in some of the experiments cited above were effective in producing alterations in serial position curves at faster rates of presentation.

\section{EXPERIMENT II}

Experiment II attempted to deal with some of the questions raised by the design of Experiment I. The single-trial paired-associate probe paradigm was again employed. Two groups of Ss were involved. All Ss were told of a delayed test and were asked to concentrate on the last pair in each list. For Ss in the delay group, an additional 5-sec delay was introduced before the probe in each list and these Ss were explicitly instructed to rehearse the last pair by saying it over and over to themselves until the probe was presented. For Ss in the control group, there was no delay between the end of a paired-associate list and the presentation of the probe. It was expected that providing additional rehearsal time and giving explicit rehearsal instructions would result in increased transfer of information to LTS about items in terminal list positions and diminished negative recency in delayed recall. No incentives were offered in Experiment II.

\section{Method}

\section{Materials and Procedure}

Forty lists of five paired associates were randomly assembled from the same word pool used in Experiment I. Two orders of probes for the immediate test were generated with the same constraints as in Experiment $I$, so that there were eight tests of each position. All lists were tape recorded at a $5 \mathrm{sec} /$ pair rate. For the control group, the probe followed the last pair in each list as though it were the first member of a sixth pair. For the delay group, an added $S \mathrm{sec}$ of silence preceded the probe. Ten seconds were permitted for S's response. For the delayed test, Ss were given a sheet containing the stimulus members of the pairs on which they had been tested originally, in a new order. No new pairs were tested. The delayed test was self-paced. With the exception of the new lists, additional delay condition, revised instructions, and the omission of incentives, the procedures used in Experiment II duplicated those of Experiment I.

\section{Subjects}

Thirty-two introductory psychology students from the University of California, Los Angeles, served as Ss, 16 in the control group and 16 in the delay group. Half of the Ss in each condition were tested with each of the two probe orders. All Ss were tested individually.

\section{Results}

Mean proportions of correct responses on immediate and delayed tests for the two experimental conditions 
are plotted as a function of input position in Fig. 2. It will be noted that imposing a delay between the end of a list and the probe resulted in somewhat lower performance on the immediate test for all but the last input position. Over all input positions, Ss in the control group remembered .57 of the pairs on the immediate test as compared to .50 for the delay group. The fact that $\mathrm{Ss}$ in the delay group perform as well as the control group on the last pair (.96 vs .95) suggests that they are indeed rehearsing these items during the delay interval. In contrast with Experiment $\mathrm{I}$, there is a well defined primacy effect for both groups in immediate recall.

Items that were correct on the immediate test and reminiscence items are both included in the data plotted in Fig. 2. The two experimental conditions together produced a total of 12 reminiscence items, 5 from the first list position, 3 each from the second and third positions, 1 from the fourth position, and none from the fifth position. Exclusion of these items would have left the shape of the delayed test curves in Fig. 2 unaffected. The control and delay groups each recalled .15 of the items correctly on the delayed test. Both groups display the familiar negative recency effect in delayed recall. No $S$ in the control group remembered any items from the fifth input position, while two Ss in the delay group remembered one fifth position item each. The predicted interaction between delay conditions, tests, and serial positions is absent.

A six-way analysis of variance (delays by probe orders by Ss by tests by serial positions by halves of the experiment), with Ss treated as a random factor nested under delays and probe orders, was performed on the probed recall scores (number of correct responses). Significant main effects of tests $[F(1,28)=772.97$, MSE $=.50]$, serial positions $[\mathrm{F}(4,112)=17.48$, $\mathrm{MSE}=1.09]$, and halves of the experiment $[\mathrm{F}(1,28)=$ 25.26 , MSE $=.68]$ were found (all ps $<.001$ ). The main effect of delays did not approach significance $[F(1,28)=$ $.70, \mathrm{MSE}=3.40]$.

The interaction between delays and tests was significant at the .05 level $[\mathrm{F}(1,28)=5.83, \mathrm{MSE}=.50]$. As mentioned above, this interaction represents the fact that the two delay conditions differ on the immediate but not on the final test. The Tests by Serial Positions interaction was significant at the .001 level $[F(4,112)=$ $187.97, \mathrm{MSE}=.32]$; items in terminal list positions were nearly always remembered on the initial test but rarely on the delayed test. The Delays by Tests by Serial Positions interaction, which might have been expected given the pattern of results in Fig. 2, failed to reach significance $[F(4,112)=1.43, \operatorname{MSE}=.32, p>.10]$.

Several other two- and three-way interactions also achieved statistical significance: Probe Orders by Serial Positions $[F(4,112)=2.64, \operatorname{MSE}=1.09, p<.05]$, Serial Positions by Halves of the Experiment $[\mathrm{F}(4,112)=4.06$, MSE $=.65, p<.01]$, Delays by Probe Orders by Serial Positions $[\mathrm{F}(4,112)=3.49, \mathrm{MSE}=1.09, \mathrm{p}<.01]$, and Probe Orders by Serial Positions by Halves of the Experiment $[\mathrm{F}(4,112)=4.38, \mathrm{MSE}=.65, \mathrm{p}<.01]$.

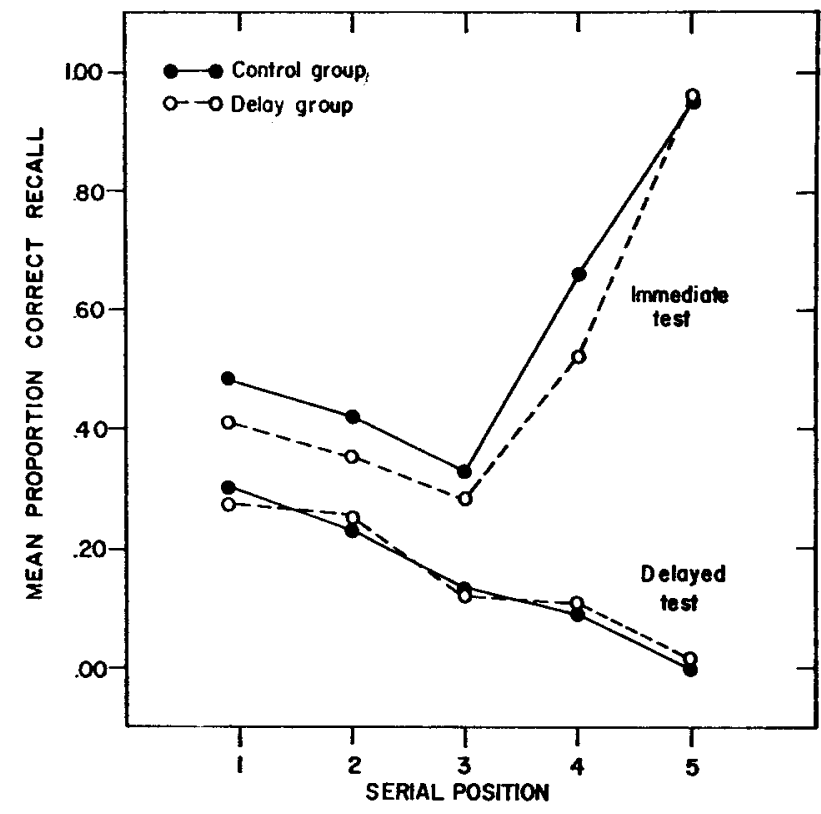

Fig. 2. Mean proportion of correct responses on immediate and delayed tests as a function of serial input position and delay condition in Experiment II.

None of these was significant in Experiment I, with the exception of the Serial Positions by Halves of the Experiment interaction, and even this interaction took somewhat different forms in the two studies. These interactions aie best attributed to item difficulty differences and will not be discussed further.

\section{DISCUSSION}

The results of the two experiments reported here are embarrassing for two-store memory model explanations of the negative recency effect which postulate that rehearsal serves to transfer information from STS to LTS. It was possible to deal with the absence of any effect of incentives on delayed recall of terminal input items in Experiment I by arguing that not enough time was available for effective rehearsal of items in this position. Such an explanation will not, however, account for the results of Experiment II. Here it was evident from the pattern of correct responses on the immediate test that Ss in the delay group rehearsed terminal input items for $7-8 \mathrm{sec}$ prior to probe presentation; recall of the terminal position for the two groups did not differ but recall of the remaining list positions was lower for the delay group than for the control group. Yet the shape of the serial position curve in delayed recall was unaffected by this additional rehearsal; recall of items in the terminal position did not improve as a function of increased rehearsal opportunity.

These results, which are not readily accommodated by Atkinson and Shiffrin's (1968) model were quite surprising, since the negative recency effect is generally held to provide strong support for this model. Atkinson and Shiffrin (1971) have reported a free recall study bearing on this issue, in which rehearsal strategies were 
manipulated. Some Ss rehearsed items by repeating them three times as they were presented, while other Ss rehearsed the current item and the two immediately preceding items. Rehearsing single items resulted in loss of the primacy effect in initial recall, while a strong recency effect remained; in delayed recall this form of rehearsal produced a flat serial position curve in which the primacy effect was absent. In addition, Bartz et al (1972) found evidence for the presence of a negative recency effect (or, rather, a positive primacy effect) only when Ss anticipated a final free recall and suggested that additional rehearsal of early items produced such results. Although these studies employed a free recall paradigm while the present experiments used a single-trial paired-associate paradigm, it is not immediately obvious why this procedural difference should matter here.

One possible explanation for the present results is that rehearsal functions solely to maintain items in STS and that deeper processing is required for more permanent storage (see Craik \& Lockhart, 1972, for a similar position). This explanation is consistent with the results of a study by Meunier, Ritz, and Meunier (1972) involving the Peterson and Peterson short-term memory paradigm. Ss were tested with filled or unfilled delay intervals of up to $18 \mathrm{sec}$. Retention was unaffected by delay intervals for the silent interval group and showed the usual loss over time for the filled interval group. However, on an unannounced test given at the end of the experimental session, the two groups did not differ in free recall of all trigrams studied. If this hypothesis is accepted, it is necessary to reinterpret the results of studies in which rehearsal has been found to be a powerful predictor of long-term retention. One route such a reinterpretation might take is that retrieval from LTS depends on the amount of information transferred to LTS, which is in turn a function of the level of processing of particular items. Deeper processing occurs only while an item resides in STS and rehearsal is necessary to maintain items in STS for processing. Thus, experimental manipulations that affect rehearsal also affect opportunities for deeper processing but extended rehearsal does not guarantee that this processing will take place.

\section{REFERENCES}

Atkinson, R. C., \& Shiffrin, R. M. Human memory: A proposed system and its control processes. In $\mathrm{K}$. W. Spence and J. T. Spence (Eds.), The psychology of learning and motivation. Vol. 2. New York: Academic Press, 1968. Pp. 89-195.

Atkinson, R. C., \& Shiffrin, R. M. The control of short-term memory. Scientific American, 1971, 225, 82-90.

Bartz, W. H., Lewis, M. Q., \& Swinton, G. Serial position effects for repeated free recall: Negative recency or positive primacy? Journal of Experimental Psychology, 1972, 96, 10-16.

Cohen, R. L. Recency effects in long-term recall and recognition. Journal of Verbal Learning \& Verbal Behavior, 1970, 9, 672-678.

Craik, F. I. M. The fate of primary memory items in free recall. Journal of Verbal Learning \& Verbal Behavior, 1970, 9, 143-148.

Craik, F. I. M., Gardiner, J. M., \& Watkins, M. J. Further evidence for a negative recency effect in free recall. Journal of Verbal Learning \& Verbal Behavior, 1970, 9, 554-560.

Craik, F. I. M., \& Lockhart, R. S. Levels of processing: A framework for memory research. Journal of Verbal Learning \& Verbal Behavior, 1972, 11, 671-684.

Darley, C. F., \& Murdock, B. B., Jr. Effects of prior free recall testing on final recall and recognition. Joumal of Experimental Psychology, 1971, 91, 66-73.

Fischler, I., Rundus, D., \& Atkinson, R. C. Effects of overt rehearsal processes on free recall. Psychonomic Science, 1970, $19,249-250$.

Glanzer, M., \& Cunitz, A. R. Two storage mechanisms in free recall. Journal of Verbal Learning \& Verbal Behavior, 1966, 5, 351-360.

Glanzer, M., \& Meinzer, A. The effects of intralist activity on free recall. Journal of Verbal Learning \& Verbal Behavior, 1967, 6, 928-935.

Harley, W. F., Jr. The effect of monetary incentive in paired-associate learning using a differential method. Psychonomic Science, 1965a, 2, 377-378.

Harley, W. F, Jr. The effect of monetary incentive in paired-associate learning using an absolute method. Psychonomic Science, 1965b, 3, 141-142.

Loftus, G. R., \& Wickens, T. D. Effect of incentive on storage and retrieval processes. Journal of Experimental Psychology, $1970,85,141-147$.

Madigan, S. A., \& McCabe, L. Perfect recall and total forget ting: A problem for models of short-term memory. Journal of Verbal Learning \& Verbal Behavior, 1971, 10, 101-106.

Marshall, P. H., \& Werder, P. R. The effects of the elimination of rehearsal on primacy and recency. Journal of Verbal Learning \& Verbal Behavior, 1972, 11, 649-653.

McCabe, L., \& Madigan, S. Negative effects of recency in recall and recognition. Journal of Verbal Learning \& Verbal Behavior, 1971, 10, 307-310.

Meunier, G. F., Ritz, D., \& Meunier, J. A. Rehearsal of individual items in short-term memory. Journal of Experimental Psychology, 1972, 95, 465-467.

Muntague, W. E., Hillix, W. A., Kiess, H. O., \& Harris, R. Variation in reports of covert rehearsal and in STM produced by differential payoff. Journal of Experimental Psychology, $1970,83,249-254$.

Palmer, S. E., \& Ornstein, P. A. Role of rehearsal strategy in serial probed recall. Journal of Experimental Psychology, $1971,88,60-66$.

Postman, L., \& Phillips, L. W. Short-term temporal changes in free recall. Quarterly Journal of Experimental Psychology, $1965,17,132-138$.

Rundus, D. Analy sis of rehearsal processes in free recall. Journal of Experimental Psychology, 1971, 89, 63-77.

Rundus, D., \& Atkinson, R. C. Rehearsal processes in free recall: A procedure for direct observation. Journal of Verbal Learning \& Verbal Behavior, 1970, 9, 99-105.

Rundus, D., Lof tus, G. R., \& Atkinson, R. C. Immediate free recall and three-week delayed recognition. Journal of Verbal Learning \& Verbal Behavior, 1970, 9, 684-688.

Thorndike, E. L., \& Lorge, I. The teacher's word book of 30,000 words New York: Columbia University Teachers College Press, 1944.

\section{NOTES}

1. This explanation was suggested by Alice Isen and Tom Trabasso.

2. The mean square error term (MSE) is given for each $F$ ratio.

(Received for publication July 11, 1973; revision received October 8,1973 .) 